Archives de sciences sociales des religions

110 | avril-juin 2000

Varia

SAMMET (Kornelia), Beruf Pfarrerin

Berlin, Arno Spitz verlag, 1998, 233 p.

Solange Wydmusch

\title{
CpenEdition
}

Journals

Édition électronique

URL : http://journals.openedition.org/assr/20708

DOI : $10.4000 /$ assr.20708

ISSN : $1777-5825$

Éditeur

Éditions de l'EHESS

Édition imprimée

Date de publication : 1 juillet 2000

Pagination : 133-134

ISBN : 2-222-96691-4

ISSN : 0335-5985

Référence électronique

Solange Wydmusch, «SAMMET (Kornelia), Beruf Pfarrerin », Archives de sciences sociales des religions

[En ligne], 110 | avril-juin 2000, document 110-94, mis en ligne le 19 août 2009, consulté le 21

septembre 2020. URL : http://journals.openedition.org/assr/20708 ; DOI : https://doi.org/10.4000/ assr.20708

Ce document a été généré automatiquement le 21 septembre 2020

(c) Archives de sciences sociales des religions 


\section{SAMMET (Kornelia), Beruf Pfarrerin}

Berlin, Arno Spitz verlag, 1998, 233 p.

\section{Solange Wydmusch}

\section{RÉFÉRENCE}

SAMMET (Kornelia), Beruf Pfarrerin, Berlin, Arno Spitz verlag, 1998, 233 p.

1 La féminisation du corps pastoral a engendré une nouvelle définition à la fois du pastorat et de la vocation. Dans son étude réalisée dans les États fédérés de Berlin et de Brandebourg, K.S. cherche à savoir si le pastorat peut être considéré comme un métier féminin. Car traditionnellement, le pastorat est masculin. Dans les différentes Églises territoriales, les femmes n'ont pu accéder à la profession que dans les années soixante. Mais leur insertion professionnelle a été couronnée de succès : en 1993, Maria Jepsens accéda à la fonction d'évêque à Hambourg.

2 S'appuyant sur une enquête quantitative ( $n=100)$ et qualitative (3 entretiens narratifs) et sur la sociologie du travail, elle cherche à mesurer le degré de féminisation de la profession tant sur le plan théologique que dans la pratique. Quel est le degré de liberté de ces pasteurs-femmes ? Comment ont-elles redéfini la profession? Enfin, comment trouvent-elles leur place dans la tension entre images féminines chrétiennes traditionnelles et images masculines paternalistes?

Il apparaît que la profession n'est nullement féminisée, les pasteurs-femmes demeurant peu nombreuses $(20 \%)$. Cependant, la profession ne peut être considérée comme exclusivement masculine. La présence majoritaire de femmes dans le vicariat et sur les bancs des facultés de théologie ne manquera pas de faire évoluer la situation. Le fait même que les jeunes pasteurs-femmes trouvent dans leur entourage professionnel des collègues féminines et que, par conséquent, elles ne sont pas contraintes de lutter pour leur insertion, fait glisser la profession du camp de profession masculine dans le camp des professions mixtes.

4 L'A. constate une sur-représentation des femmes dans l'aumônerie hospitalière. Il semble donc que la cure d'âme et l'accompagnement des personnes malades soient des 
domaines féminins. Le rôle pastoral - accompagnement personnalisé des croyants ainsi que la dimension rituelle sont particulièrement valorisés par les pasteurs-femmes dans les entretiens ; elles laissent volontiers les questions administratives aux collègues masculins. Elles sont contraintes de différencier davantage que les hommes leur vie professionnelle et leur vie familiale, leurs maris exerçant généralement une profession. Globalement, on observe donc une professionnalisation du métier de pasteur. L'originalité de cette étude réside dans son ancrage théorique. L'univers professionnel est analysé à partir de la sociologie du travail et non pas à partir de la sociologie des religions. 